\title{
Aluminium Metal Matrix Composition with Reinforcement Particles of Tungsten Carbide and Graphite
}

\author{
Shivashankar R, G V Naveen Prakash, K B Vinay
}

\begin{abstract}
Aluminium Metal Matrix composition were used in application of the aerospace and automobiles because of its strength and stiffness. Although tribological characteristics of the materials like wear resistance is low. Many research has been carried out in the particle reinforcement with the Aluminium Metal Matrix. In this paper, the several reinforced particles with the aluminium matrix were reviewed. The reinforced materials like Tungsten carbide, graphite or hybrid reinforced materials were analyzed. The stir casting process is the common technique to fabricate these materials. The reinforcement of graphite particles in aluminium materials were shows the considerable mechanical properties.
\end{abstract}

Keywords: Aluminium Metal Matrix Composition, Graphite, Hybrid Reinforced Materials, Stir Casting Process, Tribological Characteristics and Tungsten Carbide.

\section{INTRODUCTION}

Composite Materials are developed due to the more demand on materials to increases the overall performance of aerospace and automotive component. Aluminium Metal Matrix Composites (AMC) is mostly preferable in the industrial needs due to its cost and mechanical property [1]. Reinforcement particles like Aluminium oxide, Silicon carbide and graphite in fraction ranging from few percent to $60 \%$ in AMC could improve properties of metal [2]. Reinforcement composites have received the widespread attention among the researchers due to the reinforcement like ceramics particles in the smaller fraction enhances the mechanical characteristics of the materials [3]. Many research has been conducted to improve the higher specific strength, good corrosion resistance, and better tribological properties. The study shows that the harder particles reinforcement in AMC enhances the tribological and good strength than unreinforced materials and its alloys [4]. The research has been reported that the ceramics reinforcement has the limitation on AMCs such as low toughness and ductility in compared to unreinforced $\mathrm{Al}$ and alloys [5].

In metal matrix composites, stir casting is the popular production method due to its advantages of flexibility,

Revised Manuscript Received on December 5, 2019.

Shivashankar R*, Dept. of Mechanical Engineering, Vidyavardhaka College of Engineering, VVCE, India. Email: shivashankar.r@vvce.ac.in

Dr. G.V Naveen Prakash, Dept. of Mechanical Engineering, Vidyavardhaka College of Engineering, VVCE, India. Email: gvnp@ vvce.ac.in

Dr. K B Vinay, Dept. of Mechanical Engineering, Vidyavardhaka College of Engineering, VVCE, India. Email: vinaykb@ vvce.ac.in simplicity, low cost and can be used in industrial scale production [6].Mechanical properties and tribological properties has greater influences on reinforcements of steel machining chips [8]. Many researches were carried out in the AMC with various reinforcement particles to increase the mechanical property, corrosion and wear resistance $[9,10]$. In this paper, various studies involve in the fabrication of AMC with the reinforcement material of Tungsten Carbide and graphite were reviewed.

The paper is formulated as tungsten carbide reinforced AMC is reviewed in the section II, graphite particle reinforced $\mathrm{AMC}$ is reviewed in the section III, hybrid reinforcement is discussed in section IV, comparative analysis is in section $\mathrm{V}$, problem definition in the reinforced AMC is provided in section VI and conclusion is provided in section VII.

\section{REVIEW ON TUNGSTEN CARBIDE WITH ALUMINIUM MATRIX}

Aluminium based Metal Matrix reinforced with tungsten carbide to improves the mechanical properties. The researches involves in analyzing AMC with tungsten carbide were analyzed in this section.

Narayan, et al. [11] fabricated the composites such as $\mathrm{Al}_{4} \mathrm{Fe}_{3} \mathrm{C}, \mathrm{Al}_{4} \mathrm{TiC}, \mathrm{Al}_{4} \mathrm{WC}$ and $\mathrm{Al}_{4} \mathrm{Mo}_{2} \mathrm{C}$ based on die-set assembly on a hydraulic press. Materials were prepared based on the ASTM procedures. The study analysis the carbide particles of high strength added using sintered powder metallurgy composites to increases the mechanical property. The tensile and impact strength of the material is increased. The material pores are high and need to be reduced.

Narayan, et al. [12] investigate the two key strain hardening parameter in fabrication process to analyze the workability behavior or the failure zone. This method can be followed in the powder metallurgy process and especially in the die design to reduces the pores and cracks on the surface of the materials. Defects in the materials were highly reduced. The method is tested in the AMCs show that the strength and hardness of the materials is need to be improved.

Peat, et al. [13] analysis the erosion performance in the three reinforced material such as WC-CoCr MMC coating in AA 5083 using cold gas dynamic spraying.

Published By:

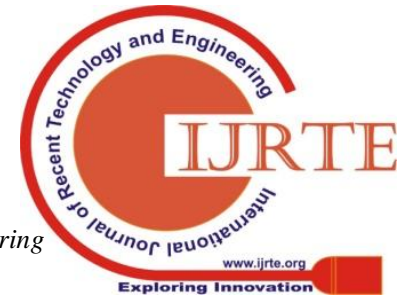


This method involves in the simultaneous spraying of reinforced materials to solve the problem of ceramic particles deposition. The thickness of the reinforced material is high on the substrate. The erosion performance of the materials is analyzed in the slurry environment. The standard tribological characteristics of the materials were also analyzed in the method. The $\mathrm{Al}_{2} \mathrm{O}_{3}$ materials shows more hardness. The erosion performance is low in this materials and need to be increased.

Huang, et al. [14] fabricate the AMC reinforced with WC particles using friction stir processing (FSP). The mechanical property of the fabricated material is evaluated and SEM image were capture to analyze the distribution. The fabricated materials show that the reinforced materials were distributed uniformly and no obvious particle clustering in stir zone. The FSP slightly reduces the WC particles with increased volume fraction. The reinforced AMC has the improved hardness and strength. The materials ductility was reduced with the increases of WC particles.

Lekatou, et al. [15] added reinforced particles of $\mathrm{TiC}$ and WC with low proposition in the AMC of melt Al 1050. The wetting agent is set as $\mathrm{K}_{2} \mathrm{TiF}_{6}$ in the casting process and mechanical stirring were applied to reduce the particle clustering. Particle distribution were considerably uniform in the fabricated material. The intermetallic phases were achieved due to the inoculation of wetting agent and fine carbide particles in the molten matrix. The sliding wear characteristics of the alloy is increased due to the reinforced particles and process. Hardness and strength are need to be increases in the material.

Li, et al. [16] presented combination of Wire and Powder Deposition by laser in the MMC fabrication. The MMC layer were deposited with $\mathrm{Ti}_{6} \mathrm{Al}_{4} \mathrm{~V}$ substrate using WPDL method. The parameter was varied to control the appearance of the MMC. The SEM, XRD and EDS were used to analyze the microstructure of these compound layers. The particles of the WC and TiC were distributed at the different location in the titanium matrix MMC layer. The WC particles were distributed in the MMC layer that provides bonding in the matrix. The strength and hardness of the materials were need to be increased.

Sachit, and Mohan [17] developed tungsten carbide reinforced aluminium LM4 alloy composites and analyzed its wear behavior. The reinforcement percentage were varied in the fabrication in the composites using Powder metallurgy technique. SEM and Energy Dispersion Spectroscopy were analyzed in the developed material. Optimization of method is carried out in the fabrication based on the Taguchi method. The hybrid reinforcement can be used to improve the hardness of the materials.

\section{REVIEW ON GRAPHITE PARTICLES IN ALUMINIUM BASED MATRIX}

Graphite particles were added in the AMC to improve the tribological behavior of the alloy. AMC with the reinforcement material of graphite were reviewed in this section.

Sharma, et al. [18] produced the AA 6082 metal matrix with the reinforcement particles of graphite using stir casting process. The different materials were fabricated based on the various proposition. The density of the material is decreased due to reinforcement of the graphite particles. The result shows that the reinforcements of the graphite particles decreases the micro and macro hardness of the materials. The Ultimate Tensile Strength (UTS) of the material is decreases in the reinforced material.

Suresh, et al. [19] developed hybrid MMC with the boron carbide and graphite in AMC. The materials were fabricated based on the stir casting method. The microstructure of the materials was analyzed. The uniform distribution of the particles was observed in the fabricated material. The optimization technique was applied in the method with various parameter. The analysis shows that the material has the better wear properties.

Sahoo, et al. [20] fabricate the AMC with the graphite reinforcement based on the solution casting. Microstructure characteristics of the materials were analyzed in the method. The surface hardness was improved in the graphite aluminium material. The surface hardness was depending up on the amount of graphite flakes on the surface and processing parameter. The strength of the material is need to be increased in the method. Bartolucci, et al. [21] fabricated the graphite aluminium composites to increase the tribological property. The tensile strength and hardness of the materials were measured. The strength and hardness of the materials is low.

Imran, et al. [22] fabricated the aluminium alloy of Al 7075 with the reinforced material of the graphite particles and bagasse-ash. The hybrid AMC is fabricated using the stir-casting method. Casting were performed in the circular metal mould with 5 circular slots of diameter of $21 \mathrm{~mm}$ and $250 \mathrm{~mm}$ length. The materials were prepared with different proposition of reinforced material. The strength of the material was tested on the ASTM standards. Results shows that the greater effects on the aluminium alloy with different reinforcement. The reinforcement paraticles were need to be uniformly distributed to reduce the surface roughness.

Lara, et al. [23] developed the Al 7075 with graphite composites based on the mechanical alloying and hot extrusion. The parameters were analyzed in the material fabrication with the mechanical properties. The experimental result shows that the considerable performance in the AMC wear resistance and hardness. The strength of the materials is need to be improved with reinforced materials.

\section{REVIEW ON HYBRID REINFORCED MMC}

Hybrid reinforced particles were used in the AMC to increase the tribological behavior. The research involves in the hybrid reinforce MMC were reviewed in this section. Zeng, et al. [24] developed aluminium silicon matrix with silicon carbide and various graphene agent using combined technique of powder metallurgy and solution mixing.

Published By:
Blue Eyes Intelligence Engineering
\& Sciences Publication


The tribological characteristics were analyzed in the dry sliding based on a ball-on-disc configuration. The SEM images were captured to analyzed the distribution of the reinforced materials. The wear rate is increases with the increases in load.

Raj, et al. [25] developed AMC and reinforced with $\mathrm{ZrSiO}_{4}$ in various proposition and solid lubricant particles using stir techniques. Reinforced particles affect the surface roughness of the material. The SEM shows that the surface characteristics in increases the reinforcement of the material. The strength and hardness of the material is need to increase. Chen, et al. [26] prepared the hybrid aluminium matrix composites reinforced with micro-SiC and nano-TiB. The SEM and Transmission Electron Microscope (TEM) were used to analyze the microstructure of the material. The strength of the material is increased using the reinforced material. Cracks were present in the materials and this affects the fatigue property.

Anish and Kumar [27] combine two materials with the dissimilar characteristics to fabricate the metal matrix. The base material is chosen as $\mathrm{Al} 7075$ with Molybdenum Disulphide $\left(\mathrm{MoS}_{2}\right)$ is used as reinforcement materials and Tungsten Carbide (WC) particulate. The stir casting process were used to fabricate the material in the various proposition. The mechanical characteristics were analyzed for the reinforced and alloy material. The result analysis shows that the fabricated material increases the hardness and strength with increases of WC. The fatigue property of the material is need to be evaluated. Dhas, and Velmurugan [28] reinforced graphite particles and tungsten carbide in the hybrid AMC.
The stir cast process were used to fabricate the material due to its cost effectiveness and better availability among other fabrication methods. The SEM analysis were used to investigate the performance of the method. Strength and hardness of the material is need to be increased.

Kumar, et al. [29] involves in the optimization process of abrasive water jet machining parameter in Aluminium and Tungsten carbide. The AMC were fabricated with the various composition of the tungsten carbide using stir casting technique. The optimized value provided by the developed method decreases the surface roughness. The strength and hardness were need to be increased. Sivananthan, et al. [30] developed aluminium oxide particles reinforced with Al6061 metal matrix alloy based on the stir casting process. Mechanical characteristics of the materials were analyzed and compared with Al 6061 alloy. The comparison shows that the mechanical property of the materials is increased. The UTS and compression strength of the Al 6061 increases with the increases of the aluminium oxides.

\section{COMPARATIVE ANALYSIS}

Aluminium based metal matrix has the excellent characteristics such as high strength, high wear resistance, high stiffness and low density. These materials were reinforced with composites like tungsten carbide, graphite to increase the tribological behavior. Table 1 provides the comparative analysis of the various composite reinforced with aluminium based metal matrix.

Table I: Comparative analysis of Aluminium based Metal Matrix composition

\begin{tabular}{|c|c|c|c|c|c|}
\hline Author(s) & $\begin{array}{c}\text { Metal } \\
\text { Matrix }\end{array}$ & $\begin{array}{c}\text { Reinforced } \\
\text { materials }\end{array}$ & Advantages & Limitations & Tribological behavior \\
\hline $\begin{array}{l}\text { Ravikumar, et } \\
\text { al. [31] }\end{array}$ & AA 6082 & Tungsten Carbide & $\begin{array}{l}\text { The hardness of the materials is } \\
\text { increases with the level of } \\
\text { tungsten carbide. } \\
\text { The tensile strength is high at } \\
\text { certain proposition. }\end{array}$ & $\begin{array}{l}\text { Strength of the material is } \\
\text { decreases. } \\
\text { Cracks were formed in the } \\
\text { material. }\end{array}$ & $\begin{array}{l}\text { For } 2 \% \text { Tungsten carbide, } \\
\text { Density }=2.65 \mathrm{~g} / \mathrm{cm}^{3} \text {, tensile } \\
\text { strength }=170 \mathrm{~N} / \mathrm{mm}^{2} \text { and } \\
\text { elongation }=5 \% .\end{array}$ \\
\hline $\begin{array}{l}\text { Alaneme, et } \\
\text { al. [32] }\end{array}$ & $\begin{array}{l}\text { Al-Mg-Si } \\
\text { alloy }\end{array}$ & $\begin{array}{l}\text { Alumina, rice husk } \\
\text { ash (RHA) and } \\
\text { graphite }\end{array}$ & $\begin{array}{l}\text { The tensile strength of the } \\
\text { material is high. }\end{array}$ & $\begin{array}{l}\text { Hardness decreases with the } \\
\text { increasing proposition of the } \\
\text { RHA and graphite } \\
\text { composition. } \\
\text { Wear resistance decreases with } \\
\text { the increases of the graphite. }\end{array}$ & $\begin{array}{l}\text { Toughness }=8 \mathrm{~J} / \mathrm{m}^{3}, \text { Tensile } \\
\text { strength }=140 \mathrm{MPa} \text {, and Vickers } \\
\text { hardness }=80 \mathrm{VHN} .\end{array}$ \\
\hline $\begin{array}{l}\text { Fenghong, et } \\
\text { al. [33] }\end{array}$ & Al6061 & $\mathrm{SiC} / \mathrm{WC}$ & $\begin{array}{l}\text { The reinforcement particles were } \\
\text { uniformly distributed without } \\
\text { clustering of the particles. } \\
\text { Hardness of the materials is } \\
\text { increased. } \\
\text { The compressive, tensile and } \\
\text { wear resistance is increased. }\end{array}$ & $\begin{array}{l}\text { Cracks, broken particles and } \\
\text { grooves were found in the } \\
\text { material. }\end{array}$ & $\begin{array}{l}\text { Hardness }=78 \mathrm{HV}, \text { UTS }=140 \\
\mathrm{~N} / \mathrm{mm}^{3}, \quad \text { and Compression } \\
\text { strength }=300 \mathrm{~N} / \mathrm{mm}^{3} .\end{array}$ \\
\hline $\begin{array}{l}\text { Ponugoti, et } \\
\text { al. [34] }\end{array}$ & $\mathrm{Al6061}$ & $\begin{array}{l}\text { Graphite and } \\
\text { Tungsten carbide }\end{array}$ & $\begin{array}{l}\text { Optimal tribological } \\
\text { characteristics is provided. }\end{array}$ & $\begin{array}{l}\text { Strength and hardness of the } \\
\text { materials is need to be } \\
\text { evaluated. }\end{array}$ & Wear rate $=3 \mathrm{~m} / \mathrm{s}$. \\
\hline $\begin{array}{l}\text { Dalmis, et al. } \\
{[35]}\end{array}$ & ZA27 & $\begin{array}{l}\text { Nano-sized graphite } \\
\text { (Gr) and boron } \\
\text { carbide (B4C) }\end{array}$ & Density is decreased. & Tensile strength is decreased. & $\begin{array}{l}\text { Density }=4,72 \mathrm{~g} / \mathrm{cm}^{3} \text { and UTS }= \\
98 \mathrm{MPa} .\end{array}$ \\
\hline $\begin{array}{l}\text { Mohanavel, et } \\
\text { al. [36] }\end{array}$ & AA6351 & $\begin{array}{l}\text { Graphite and } \\
\text { alumina } \\
\text { particulates } \\
\text { reinforced. }\end{array}$ & $\begin{array}{l}\text { Tribological characteristics were } \\
\text { improved. }\end{array}$ & Reinforcement is not uniform. & Density $=2.6761 \mathrm{~g} / \mathrm{cm}^{3}$. \\
\hline $\begin{array}{l}\text { Dhas, et al. } \\
{[37]}\end{array}$ & AA 5052 & $\begin{array}{l}\text { Tungsten carbide } \\
\text { and graphite }\end{array}$ & Surface roughness is low. & $\begin{array}{l}\text { Strength and hardness is need } \\
\text { to be evaluate. }\end{array}$ & Surface roughness $=0.0408 \mu \mathrm{m}$. \\
\hline
\end{tabular}




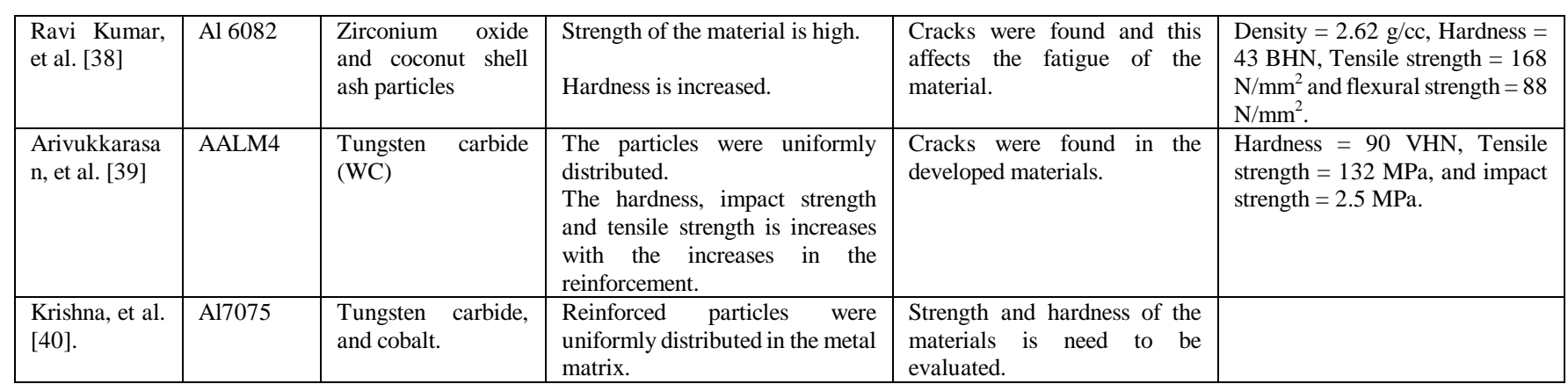

\section{PROBLEM DEFINITION}

The several reinforcement particles in AMC were analyzed and some problems has been observed. The problems in the reinforced composited in Aluminium matrix were given below:

1. Aluminium based Metal Matrix Composites were highly used in the aerospace and automobiles application due to its strength and stiffness. But AMC has the low tribological behavior like low wear resistance.

2. AMC were reinforced with the particles to increases the tribological behavior of the material. This affects the strength and hardness of the material, and also affects the bond of the materials.

3. Some of the particles like $\mathrm{SiC}$ provides the significant improvement in the mechanical and physical properties, this leads to the poor machined surface quality and low tool life especially in the machining AMC.

4. The reinforced particles should be uniformly distributed in the metal matrix and the distribution is not uniform, this affects the surface roughness of the material and limits its application.

5. Ceramics particles such as tungsten carbide or aluminia is difficult to achieve due to its limited deformability in solid state.

From the analysis of the various material compositions, the combination of tungsten carbide and graphite composition in Aluminium matrix shows the promising performance in terms of material strength and surface roughness due to its tribological behavior. Although, the investigation is need to performed for the combination of tungsten carbide and graphite in 6xxx series of aluminium material. The Al 6061 is most versatile material having good mechanical properties and corrosion resistance with commercially available. Al 6061 material is most commonly used in the automobile manufacturing components. Therefore, investigation is need to be performed with combination of tungsten carbide and graphite composites in Al 6061 matrix. The Al 6061 T6 material has the high Ultimate Tensile Strength and can be used to investigate with tungsten carbide and graphite composites.

\section{CONCLUSION}

This paper analysis the several reinforced particles in the AMC to analyzed its advantages and limitations. The particles like tungsten carbide and graphite in the aluminium matrix were reviewed. This shows that the tungsten carbide improves the strength and hardness of the material and affects the fatigue performance of material. This is difficult to uniformly distributed the tungsten in the metal matrix due to the large density gradient. The graphite particles were reinforced with the metal matrix that improve the hardness of the material. In the analysis, this is clear that to increase tribological behavior and the hardness of the material by proper uniform reinforcement.

\section{REFERENCES}

1. P.S. Reddy, R. Kesavan, \& B.V. Ramnath, "Investigation of mechanical properties of aluminium 6061-silicon carbide", boron carbide metal matrix composite. Silicon, vol. 10, 2018, pp. 495-502.

2. R.D. Manikonda, S. Kosaraju, K.A. Raj, \& N. Sateesh, "Wear Behavior Analysis of Silica Carbide Based Aluminum Metal Matrix Composites," Materials Today: Proceedings, vol. 5, 2018, pp. 20104-20109.

3. I. Kakaravada, A. Mahamani, \& V. Pandurangadu, "Turning Studies on A356-TiB 2/TiC In Situ Reinforced Composites," In Advances in Manufacturing Processes, 2019, 37-48.

4. A.P. Reddy, P.V. Krishna, \& R.N. Rao, "Tribological Behaviour of Al6061-2SiC-xGr Hybrid Metal Matrix Nanocomposites Fabricated through Ultrasonically Assisted Stir Casting Technique," Silicon, 2019, pp. $1-19$

5. K.K. Alaneme, A.V. Fajemisin, \& N.B. Maledi, "Development of aluminium-based composites reinforced with steel and graphite particles: structural, mechanical and wear characterization," Journal of Materials Research and Technology, vol. 8, 2019, pp. 670-682.

6. A.G. Lekatou, N. Gkikas, V. Gousia, K. Lentzaris, \& A.E. Karantzalis, "Effects of in situ intermetallics on the microstructural array and saline corrosion performance of cast Al/WCp composites," Journal of Materials Engineering and Performance, vol. 27, 2018, pp. 5164-5176.

7. K.K. Alaneme, M.O. Bodunrin, \& A.A. Awe, "Microstructure, mechanical and fracture properties of groundnut shell ash and silicon carbide dispersion strengthened aluminium matrix composites," Journal of King Saud University-Engineering Sciences, vol. 30, 2018, pp. 96-103.

8. R. Venkatesh, \& V.S. Rao, "Thermal, corrosion and wear analysis of copper based metal matrix composites reinforced with alumina and graphite," Defence Technology, vol. 14, 2018, pp. 346-355.

9. C. Fenghong, C. Chang, W. Zhenyu, T. Muthuramalingam, \& G. Anbuchezhiyan, "Effects of silicon carbide and tungsten carbide in Aluminium metal matrix composites," Silicon, 2019, pp. 1-8.

10. V. Kumar, R.D. Gupta, \& N.K. Batra, "Comparison of Mechanical Properties and effect of sliding velocity on wear properties of $\mathrm{Al} 6061, \mathrm{Mg}$ 4\%, Fly ash and $\mathrm{Al} 6061, \mathrm{Mg} 4 \%$, Graphite 4\%, Fly ash Hybrid Metal matrix composite," Procedia materials science, vol. 6, 2014, pp. 1365-1375.

11. S. Narayan, \& A. Rajeshkannan, "Hardness, tensile and impact behaviour of hot forged aluminium metal matrix composites," Journal of Materials Research and Technology, vol. 6, 2017, pp. 213-219.

12. S. Narayan, \& A. Rajeshkannan, "Studies on formability of sintered aluminum composites during hot deformation using strain hardening parameters," Journal of Materials Research and Technology, vol. 6, 2017, pp. 101-107. 
13. T. Peat, A. Galloway, A. Toumpis, P. McNutt, \& N. Iqbal, "The erosion performance of particle reinforced metal matrix composite coatings produced by co-deposition cold gas dynamic spraying," Applied Surface Science, vol. 396, 2017, pp. 1623-1634.

14. G. Huang, W. Hou, \& Y. Shen, "Evaluation of the microstructure and mechanical properties of WC particle reinforced aluminum matrix composites fabricated by friction stir processing," Materials Characterization, vol. 138, 2018, pp. 26-37.

15. A. Lekatou, A.E. Karantzalis, A. Evangelou, V. Gousia, G. Kaptay, Z Gácsi, P. Baumli, \& A. Simon, "Aluminium reinforced by WC and TiC nanoparticles (ex-situ) and aluminide particles (in-situ): Microstructure, wear and corrosion behaviour," Materials \& Design, vol. 65, 2015, pp 1121-1135.

16. F. Li, Z. Gao, L. Li, \& Y. Chen, "Microstructural study of MMC layers produced by combining wire and coaxial WC powder feeding in laser direct metal deposition," Optics \& Laser Technology, vol. 77, 2016, pp. 134-143.

17. T.S. Sachit, \& N. Mohan, "Wear rate optimization of tungsten carbide (WC) nano particles reinforced aluminum LM4 alloy composites using Taguchi techniques," Materials Research Express, vol. 6, 2019, pp 066564.

18. O.A. Abdulrazzaq, V. Saini, S. Bourdo, E. Dervishi, and A.S. Biris, "Particulate Science \& Technology," An International Journal, vol. 31 pp. $427-442$.

19. V. Suresh, N. Hariharan, S. Paramesh, M.P. Kumar, \& P.A. Prasath, "Tribological behaviour of aluminium/boron carbide (B4C)/graphite ( $\mathrm{Gr}$ ) hybrid metal matrix composite under dry sliding motion by using ANOVA," International Journal of Materials and Product Technology, vol. 53, 2016, pp. 204-217.

20. B. Sahoo, R. Kumar, J. Joseph, A. Sharma, \& J. Paul, "Preparation of aluminium 6063-graphite surface composites by an electrical resistance heat assisted pressing technique," Surface and Coatings Technology, vol. 309,2017 , pp. 563-572.

21. S.F. Bartolucci, J. Paras, M.A. Rafiee, J. Rafiee, S. Lee, D. Kapoor, \& N. Koratkar, "Graphene-aluminum nanocomposites," Materials Science and Engineering: A, vol. 528, 2011, pp. 7933-7937.

22. M. Imran, A.A. Khan, S. Megeri, \& S. Sadik, "Study of hardness and tensile strength of Aluminium-7075 percentage varying reinforced with graphite and bagasse-ash composites," Resource-Efficient Technologies, vol. 2, 2016, pp. 81-88

23. R. Deaquino-Lara, N. Soltani, A. Bahrami, E. Gutiérrez-Castañeda, E García-Sánchez, \& M.A.L. Hernandez-Rodríguez, "Tribological characterization of A17075-graphite composites fabricated by mechanical alloying and hot extrusion," Materials and Design, vol. 67, 2015, pp. 224-231.

24. X. Zeng, J. Yu, D. Fu, H. Zhang, \& J. Teng, "Wear characteristics of hybrid aluminum-matrix composites reinforced with well-dispersed reduced graphene oxide nanosheets and silicon carbide particulates," Vacuum, 155 2018, pp. 364-375

25. R.R. Raj, \& H. Kanagasabapathy, "Influence of abrasive water jet machining parameter on performance characteristics of AA7075-ZrSiO4-hBN hybrid metal matrix composites," Materials Research Express, vol. 5, 2018, pp. 106509.

26. X. Chen, D. Fu, J. Teng, \& H. Zhang, "Hot deformation behaviour and mechanism of hybrid aluminum-matrix composites reinforced with micro-SiC and nano-TiB2," Journal of Alloys and Compounds, vol. 753 2018, pp. 566-575

27. A. Anish, \& M.A. Kumar, "Characterization of aluminium matrix reinforced with tungsten carbide and molybdenum disulphide hybrid composite," In IOP Conference Series: Materials Science and Engineering, vol. 402, 2018, pp. 012006.

28. D.E.J. Dhas, \& C. Velmurugan, "Mathematical modeling of the corrosion response of aluminium 5052/tungsten carbide/graphite hybrid composite: Mathematische Modellierung der Korrosionsreaktion von Aluminium 5052/Wolframkarbid/Graphit-Hybrid-Verbundwerkstoff," Materialwissenschaft und Werkstofftechnik, vol. 49, 2018, pp. $1335-1345$.

29. K.R. Kumar, V.S. Sreebalaji, \& T. Pridhar, "Characterization and optimization of Abrasive Water Jet Machining parameters of aluminium/tungsten carbide composites," Measurement, vol. 117, 2018 pp. 57-66.

30. S. Sivananthan, V.R. Reddy, \& C.S.J. Samuel, "Preparation and evaluation of mechanical properties of $6061 \mathrm{Al}-\mathrm{Al} 2 \mathrm{O} 3$ metal matrix composites by stir casting process," Materials Today: Proceedings, 2019

31. K. Ravikumar, K. Kiran, \& V.S. Sreebalaji, "Characterization of mechanical properties of aluminium/tungsten carbide composites," Measurement, vol. 102, 2017, pp. 142-149.

32. K.K. Alaneme, \& K.O. Sanusi, "Microstructural characteristics, mechanical and wear behaviour of aluminium matrix hybrid composites reinforced with alumina, rice husk ash and graphite," Engineering Science and Technology, an International Journal, vol. 18, 2015, pp. 416-422.

33. E.E. Feldshtein, L.N. Dyachkova, K. Adamczuk, S. Legutko, \& G.M Królczyk, "Synergy effect of ultrafine tungsten, silicon carbides and graphite microadditives on the Fe-based MMCs properties using the simplex lattice design," Journal of Alloys and Compounds, vol. 757, 2018, pp. 31-38

34. G.R. Ponugoti, P.R. Vundavilli, \& A.G. Krishna, "Springer, Singapore Optimization of Tribological Properties of Al6061/9\% Gr/WC Hybrid Metal Matrix Composites Using FGRA," In Advances in Manufacturing Technology, 2019, pp. 485-492.

35. R. Dalmis, H. Cuvalci, A. Canakci, O. Guler, \& E. Celik, "The Effect of Mechanical Milling on Graphite-Boron Carbide Hybrid Reinforced ZA27 Nanocomposites," Arabian Journal for Science and Engineering, vol. 43 , 2018, pp. 1113-1124.

36. V. Mohanavel, K. Rajan, M. Ravichandran, S.S. Kumar, M. Balamurugan, \& C. Jayasekar, "Springer, Singapore. Physical and Tribological Behaviour of Dual Particles Reinforced Metal Matrix Composites," In Innovative Design, Analysis and Development Practices in Aerospace and Automotive Engineering (I-DAD 2018), 2019, pp. 339-347.

37. D.E.J. Dhas, C. Velmurugan, \& K.L.D. Wins, "Investigations on the effect of tungsten carbide and graphite reinforcements during spark erosion machining of aluminium alloy (AA 5052) hybrid composite," Silicon, vol. 10, 2018, pp. 2769-2781.

38. K.R. Kumar, T. Pridhar, \& V.S. Balaji, "Mechanical properties and characterization of zirconium oxide ( $\mathrm{ZrO} 2)$ and coconut shell ash (CSA) reinforced aluminium (Al 6082) matrix hybrid composite," Journal of Alloys and Compounds, 765, 2018, pp. 171-179.

39. S. Arivukkarasan, V. Dhanalakshmi, B. Stalin, \& M. Ravichandran, "Mechanical and tribological behaviour of tungsten carbide reinforced aluminum LM4 matrix composites," Particulate Science and Technology, vol. 36, 2018, pp. 967-973.

40. U.G. Krishna, V. Auradi, B. Vasudeva, \& S.A. Kori, "Processing and Microstructural Characterization of Cermet-Reinforced Aluminium Matrix Composite by Solidification Process," Transactions of the Indian Institute of Metals, vol. 71, 2018, pp. 2851-2854.

\section{AUTHORS PROFILE}

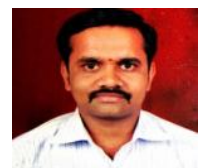

Mr. Shivashankar $\mathbf{R}$ is Assistant Professor in the Department of Mechanical Engineering, VVCE, Mysuru. $\mathrm{He}$ did his BE in Mechanical Engineering from TCE, Gadag in the year 2008 and M.Tech in Machine Design from BIET Davangere in the year 2010. He is life membe of Indian Society of Technical Education (ISTE). His areas of interest include composite materials, Tribology.

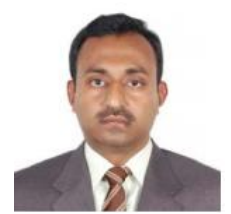

Dr G V Naveen Prakash received his BE degree in Mechanical Engineering from University of Mysore. M.Tech in Production Engineering Systems Technology from VTU and Ph.D in Mechanical Engineering from VTU in 2011. His major research interest areas are condition monitoring, composite and Biodiesel. He is working as Professor and Head in the Department of Mechanical Engineering, VVCE, Mysuru. He has more than 16 years of teaching, 10yeras of research and 1.5 years of industry experience. He is a life member of ISTE, SME and IE(I)

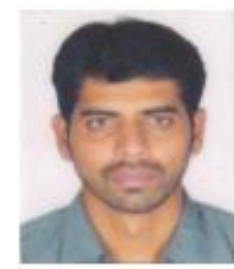

Dr. Vinay K B working as Associate professor at Mechanical Engineering Department, VVCE, Mysore. He completed B.E, M.Tech and Ph.D in Mechanical engineering from University of Mysore and Visvesvaraya Technological University. He has presented 16 papers in national and internationa conferences and published 07 papers in Journals. Teaching experience 15 years. Research interests are Incubation, Heat Transfer and fluid flow, Quality Management, Operations Management, Entrepreneurship, Engineering system Design. Life member of ISTE. 